\title{
PRELIMINARY EXPERIMENTAL INVESTIGATION OF CUT-RESISTANT MATERIALS: A BIOMIMETIC PERSPECTIVE
}

\author{
Paulina Kropidłowska¹, Emilia Irzmańska1', Jacek Sawicki² \\ 1 Central Institute for Labour Protection - National Research Institute, Department of Personal Protective Equipment, 48 Wierzbowa, Lodz, Poland \\ 2 Institute of Materials Science and Engineering, Lodz University of Technology, 1/15 Stefanowskiego, 90-924 Lodz, Poland \\ *Corresponding author: E-mail: pakro@ciop.lodz.pl, emirz@ciop.lodz.pl; jacek.sawicki@p.lodz.pl
}

\begin{abstract}
:
The objective of the work was the preliminary experimental investigation of cut-resistant materials including a biomimetic perspective. The effects of the cutting were expressed as static and dynamic cut resistance of the following materials: knitted fabrics, woven fabrics, continuously coated knitted fabrics, and dot-coated knitted fabrics. The cutting process gives rise to frictional forces, but the current test methods for cut-resistant gloves are not designed to measure them. Therefore additionally, the cut resistance of the material was evaluated using a modified procedure based on the standard EN 1082-1, taking into consideration grip strength tests to assess if there is a potential correlation between cut resistance and anti-slip properties.
\end{abstract}

\section{Keywords:}

Protective gloves; cut-resistant materials; grip strength properties; biomimetic

\section{Introduction}

One way of preventing hand injury is the use of gloves that are fit for purpose in protective and ergonomic terms [1-3]. Worker's hands, involved in all occupational tasks, are directly exposed to various hazardous workplace factors. Indeed, upper limb injuries comprise the largest group of accidents at work (as much as $39.2 \%$ in 2017) [4].

Except for some specialist protective devices (such as metal mesh gloves), cut-resistant gloves are usually manufactured from p-aramid yarns $($ Kevlar $\AA$, Kevlar $®$ Kleen $₫$, Kevlar $®$ Plus $₫$, and Kevlar $\AA$ Armor from DuPont; Twaron $®$ and Twaron $®$ Premium Line from Teijin) or core-spun yarns, with cores made of stainless steel or cut-resistant textile yarns and with sheaths made of textile yarns, polyethylene yarns (Dyneema ${ }^{\circledR}$ from DSM; Spectra $\AA$, Spectra $\AA$ Guard $\AA$, and Spectra $\AA$ Guard $\AA$ CX from Honeywell), glass fibers, a combination of the above, as well as from cotton, polyamide (and nylon), polyester, elastane, and Lycra fibers [5-8]. To impart anti-slip properties and facilitate the gripping of smooth and slippery objects, the palmar or both palmar and dorsal aspects of gloves may be coated with a continuous layer of polymer, usually polyvinyl chloride, polyurethane, silicone, nitrile rubber, or natural rubber. Such treatment not only improves the functional properties of gloves but also enhances their mechanical resistance [9-12].

For gloves to be deemed suitable for protection against mechanical injury, they must meet several protective and functional requirements laid down in Regulation 2016/425 of the European Parliament and the Council [13]. A particularly important protective parameter in this context is cut resistance. The basic standard specifying the requirements and test methods for cut-resistant gloves is EN 388:2016 + A1:2018 [14], with EN ISO 13997:1999 [15] also being increasingly used. The test methods described in those standards differ in that EN 388:2016 + A1:2018 employs a round cutting blade applying constant (static) cutting force, while EN ISO 13997 uses a straight blade applying variable (dynamic) cutting force.

According to the literature, the higher the force needed to cut through a material, the greater should be its cut resistance. The two major components of cutting force are normal force and abrasive force, which differ between protective materials [16]. According to Lara et al. [17], a greater friction coefficient may either enhance or reduce the cut resistance of a material, depending on its thickness, Young modulus, and macrostructure. It has also been shown that in fabrics knitted from aramid yarns, frictional forces are very low as compared to neoprene materials, which translates into differences in cutting forces between coated and uncoated materials [18].

As mentioned above, the cutting process gives rise to frictional forces, but the current test methods for cut-resistant gloves are not designed to measure them. In the case of protective gloves, this parameter can be determined indirectly by evaluating their anti-slip properties associated with gripping objects during manual work $[6,10]$. The friction measurement methods widely described in the literature were designed for evaluating the pilling performance of flat textile materials in the context of the esthetic appearance of clothing; these include the Kawabata method, the sliding fabric method, and estimation of the coefficient of friction between parallel fabric surfaces [19-22].

Measurement of both cutting and frictional forces in cutting is of importance in evaluating alternative bionics-inspired 
materials with potential applications for protective gloves. The design of protective devices is becoming an increasingly complex process requiring interdisciplinary knowledge in terms of both product development and assessment, going beyond the prescribed standards. An example of such an approach is seeking inspiration for innovative technological solutions in the natural environment [23-27]. Lightweight structures characterized by high mechanical resistance are indispensable in many engineering applications as biomimetic solutions have been shown to possess superior mechanical properties as compared to conventionally engineered ones [28, 29].

The present paper describes a preliminary study of bionicsinspired textile materials made of cut-resistant yarns, coated and not-coated with polymeric paste. The materials were evaluated both according to the relevant standards and using other methods to reflect the important aspects of the cutting process. The applied methodology accounted for different types of cutting forces (static and dynamic) as well as macroscopic frictional forces, which were assessed using non-standard grip strength measurements. The results obtained from the various methods used were compared and analyzed for correlations to determine whether the methods are suitable for reliable evaluation of cut-resistant materials.

\section{Materials}

The study involved four commercially available textile materials used in protective gloves, i.e., knitted fabrics, woven fabrics, continuously coated knitted fabrics, and dot-coated knitted fabrics, characterized in Table 1. The studied gloves were made of aramid, glass, and carbon fibers.

\section{Methods}

The four selected groups of textile materials were tested for static and dynamic cut resistance as well as grip strength. Before testing, samples were acclimatized at $23 \pm 2^{\circ} \mathrm{C}$ and relative air humidity of $50 \pm 5 \%$ for $24 \mathrm{~h}$.

\subsection{Static cut resistance testing}

Static cut resistance was evaluated according to EN $388: 2016+A 1: 2018$ with a constant load applied to the blade resulting in a force of $(5 \pm 0.5) \mathrm{N}$. During the test, a rotating circular blade with a diameter of $(45 \pm 0.5) \mathrm{mm}$, a thickness of $(0.3 \pm 0.03) \mathrm{mm}$, and a total cutting angle of $30-35^{\circ}$. The horizontal movement was $50 \mathrm{~mm}$ long with the blade rotating completely $\left(360^{\circ}\right)$ in the opposite direction. The sinusoidal cutting speed was $(8 \pm 2) \mathrm{cm} / \mathrm{s}$. Test results were recorded as in Table 2.

$\overline{C_{n}}$ represents the average number of cycles for the control specimen before and after the cut of the test specimen $T_{n}$ and is calculated from the following equation:

$$
\overline{C_{n}}=\frac{\left(C_{n}+C_{n+1}\right)}{2}
$$

A unitless cut resistance index $(I)$ was calculated for every test specimen according to Eq. (2).

$$
I=\frac{1}{5} \sum_{n=1}^{5} i_{n} \text { where } i_{n}=\frac{\left(\overline{C_{n}}+T_{n}\right)}{\overline{C_{n}}}
$$

The resulting index values were used to assign cut-resistant performance levels to the specimens according to Table 3.

\subsection{Dynamic cut resistance testing}

Dynamic cut resistance testing under variable load applied to the blade was conducted by following EN ISO 13997:1999 using an apparatus from P.I. Kontech (Poland). Samples were mounted on a metal cylinder with a radius of $(38 \pm 0.5) \mathrm{mm}$ and a straight blade was drawn across the curvature of the cylinder with the plane of the blade at an angle of $90 \pm 2^{\circ}$ to the long axis of the cylinder. The cutting edge of the blade was $(74 \pm 0.2) \mathrm{mm}$ long, $(18.5 \pm 0.2) \mathrm{mm}$ wide, and $(1.0 \pm 0.5) \mathrm{mm}$ thick. The angle of the cutting edge was $22^{\circ}$. During the test, a variable force ranging from $1.0 \mathrm{~N}$ to $200.0 \mathrm{~N}$ was applied to the blade. The cutting rate was $(2.5 \pm 0.5) \mathrm{cm} / \mathrm{s}$. Each result

Table 3. Cut resistance requirements [14]

\begin{tabular}{|c|c|}
\hline Performance level & Cut resistance (Index, $\boldsymbol{I}$ ) \\
\hline $\mathbf{1}$ & 1.2 \\
\hline $\mathbf{2}$ & 2.5 \\
\hline $\mathbf{3}$ & 5.0 \\
\hline $\mathbf{4}$ & 10.0 \\
\hline $\mathbf{5}$ & 20.0 \\
\hline
\end{tabular}

Table 2. Calculation of cut resistance index [14]

\begin{tabular}{|c|c|c|c|c|}
\hline Sequence & $\begin{array}{c}\boldsymbol{C}_{\mathrm{n}} \\
\text { Control specimen }\end{array}$ & $\begin{array}{c}\boldsymbol{T} \\
\text { Test specimen }\end{array}$ & $\begin{array}{c}\boldsymbol{C}_{\mathrm{n}+1} \\
\text { Control specimen }\end{array}$ & $\begin{array}{c}\boldsymbol{I} \\
\text { Index }\end{array}$ \\
\hline $\mathbf{1}$ & $C_{1}$ & $T_{1}$ & $C_{2}$ & $i_{1}$ \\
\hline $\mathbf{2}$ & $C_{2}$ & $T_{2}$ & $C_{3}$ & $i_{2}$ \\
\hline $\mathbf{3}$ & $C_{3}$ & $T_{3}$ & $C_{4}$ & $i_{3}$ \\
\hline $\mathbf{4}$ & $C_{4}$ & $T_{4}$ & $C_{5}$ & $i_{5}$ \\
\hline 5 & $C_{5}$ & $T_{5}$ & $C_{6}$ & $I_{5}$ \\
\hline
\end{tabular}


Table 1. Textile materials used in the study

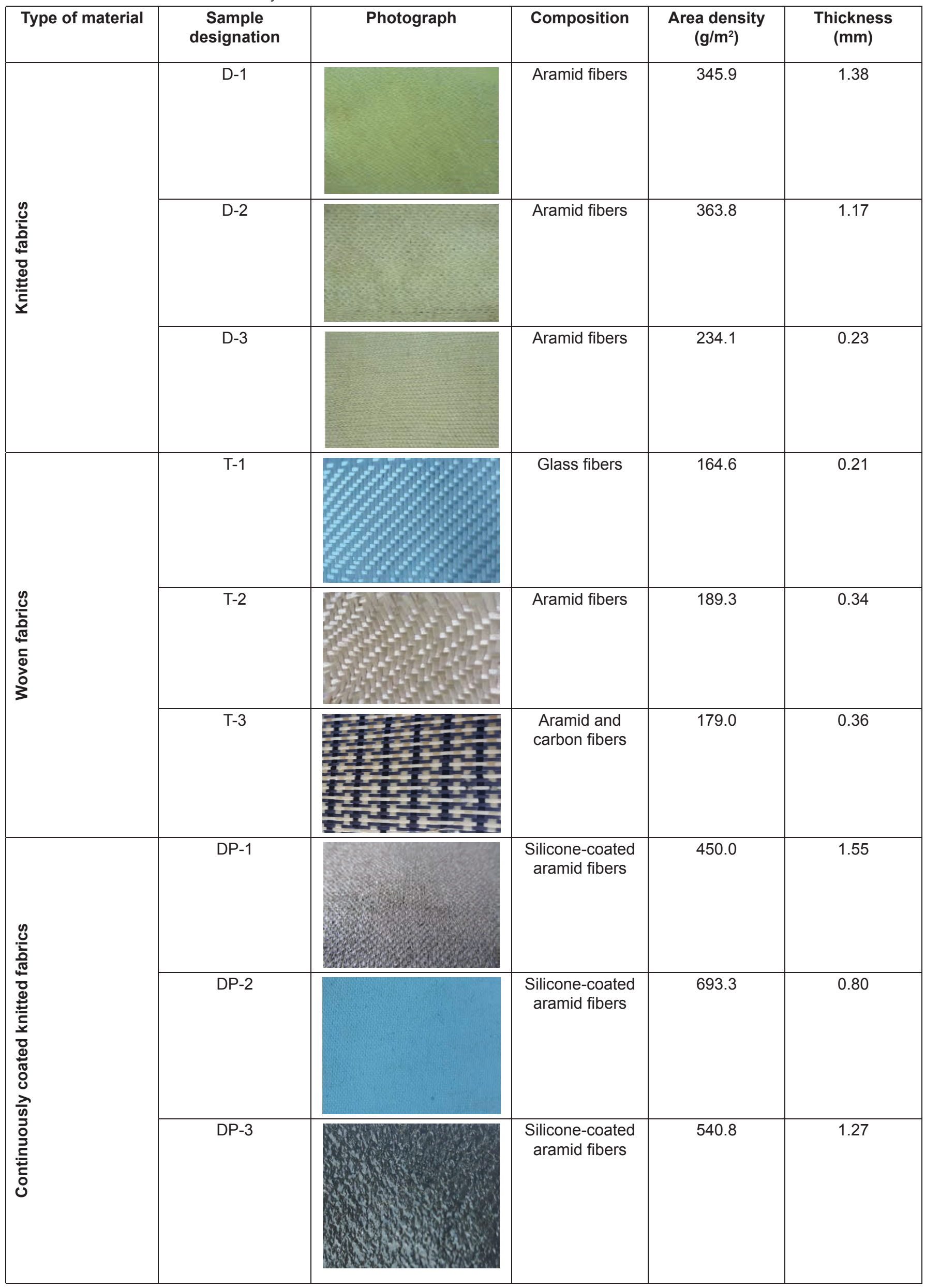


Table 1 continued. Textile materials used in the study

\begin{tabular}{|c|c|c|c|c|c|}
\hline Type of material & $\begin{array}{c}\text { Sample } \\
\text { designation }\end{array}$ & Photograph & Composition & $\begin{array}{l}\text { Area density } \\
\left(\mathrm{g} / \mathrm{m}^{2}\right)\end{array}$ & $\begin{array}{l}\text { Thickness } \\
\text { (mm) }\end{array}$ \\
\hline \multirow{3}{*}{ 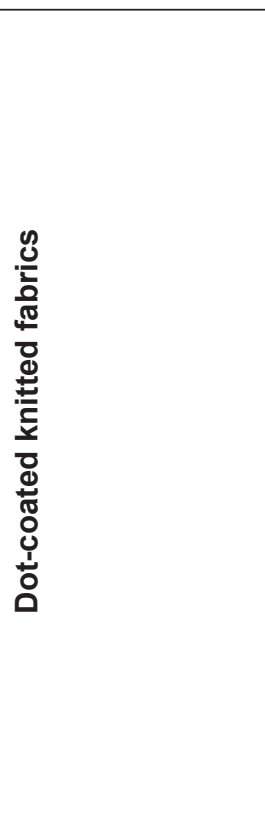 } & $\mathrm{DN}-1$ & $8080898)$ & $\begin{array}{l}\text { Dot-coated } \\
\text { aramid fibers }\end{array}$ & 555.0 & 3.34 \\
\hline & DN-2 & 898989 & $\begin{array}{l}\text { Dot-coated } \\
\text { aramid fibers }\end{array}$ & 614.0 & 2.68 \\
\hline & DN-3 & 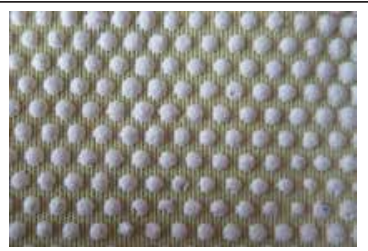 & $\begin{array}{l}\text { Dot-coated } \\
\text { aramid fibers }\end{array}$ & 573.0 & 2.76 \\
\hline
\end{tabular}

was corrected for blade sharpness. Performance levels were assigned to different cutting force levels according to Table 4.

\subsection{Grip strength test}

The grip strength properties of materials used in protective gloves were evaluated using a modified procedure based on the standard EN 1082-1 [30]. The modification concerned the type of specimens studied: while the standard test involves entire gloves, the tests performed in this study involved samples of glove materials. The measurement setup consisted of an adjustable height table on which there was a metal cylinder with a diameter of $30 \mathrm{~mm}$ coupled to a dynamometer. Samples measuring $150 \times 150 \mathrm{~mm}$ were cut out from the studied glove materials and placed around the cylinder within the markers. During tests, the human subject lightly squeezed the cylinder with the sample wrapped around it with his or her right hand. Then, the subject pulled the cylinder with maximum force reached over a time of at least $5 \mathrm{~s}$, which could be maintained over $10 \mathrm{~s}$. During a successful trial, the sample could not move to the cylinder markers (its initial position). The grip force exerted on the cylinder with a given sample was read from the dynamometer (Andilog, USA). The test was done in quintuplicate for each sample, with a 15 min rest between consecutive trials. The measurement setup and procedure are presented in Figure 1.

Table 4. Performance levels of materials tested with variable cutting force [15]

\begin{tabular}{|c|c|c|c|c|c|c|}
\hline Performance levels & $\begin{array}{c}\text { Level } \\
\text { A }\end{array}$ & $\begin{array}{c}\text { Level } \\
\text { B }\end{array}$ & $\begin{array}{c}\text { Level } \\
\text { C }\end{array}$ & $\begin{array}{c}\text { Level } \\
\text { D }\end{array}$ & $\begin{array}{c}\text { Level } \\
\text { E }\end{array}$ & $\begin{array}{c}\text { Level } \\
\text { F }\end{array}$ \\
\hline Cutting force (N) & 2 & 5 & 10 & 15 & 22 & 30 \\
\hline
\end{tabular}

\subsection{Statistical analysis}

The results were analyzed using SPSS Statistics 25.0 software. Pearson's $r$ correlation coefficient was calculated by a posteriori bootstrapping with 1,000 replicates. Statistical significance was adopted at $p<0.05$. The results of static and dynamic cut resistance tests were compared with those of grip strength tests to identify correlations.

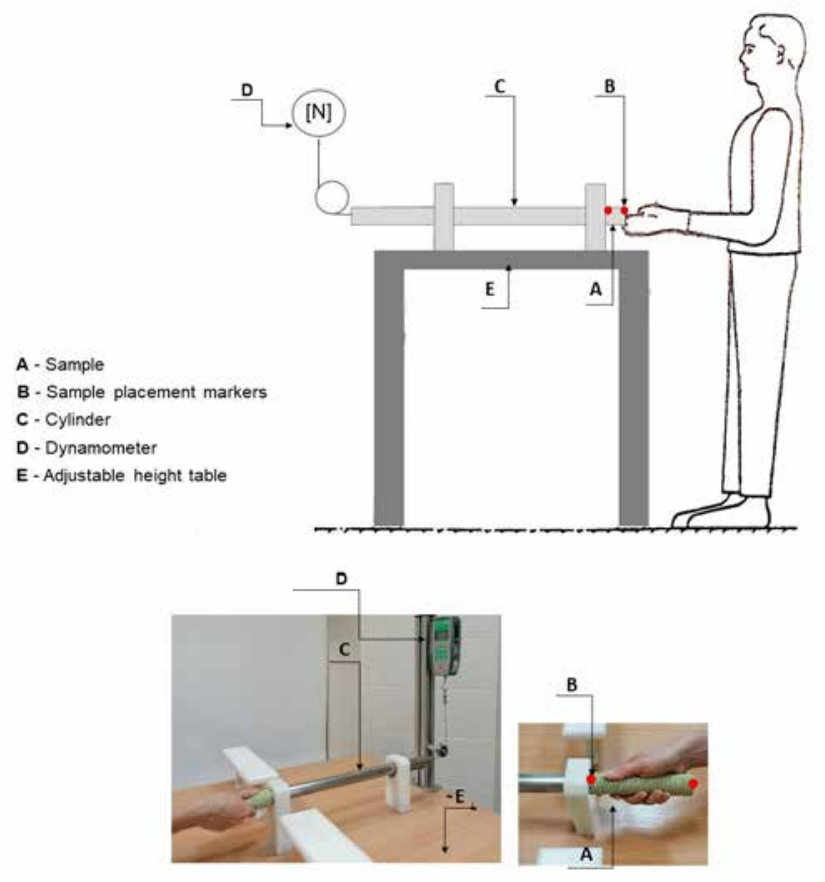

Figure 1. Diagram and photographs of the grip strength test. 


\section{Results and discussion}

\subsection{Laboratory test results}

Cut resistance and grip strength results for four groups of materials are presented below to establish correlations between static and dynamic cut resistance and grip strength. Static and dynamic cut resistance results are given in Table 5 and Figure 2 while grip strength results are shown in Figure 3.

The presented static and dynamic cut resistance results reveal high variability in the performance of commercially available materials used in protective gloves against mechanical hazards. Knitted aramid fabrics were characterized by performance levels 2, 4, and 5 in terms of static cutting and levels $B$ and $C$ in terms of dynamic cutting. Among the tested knitted fabrics, D-1

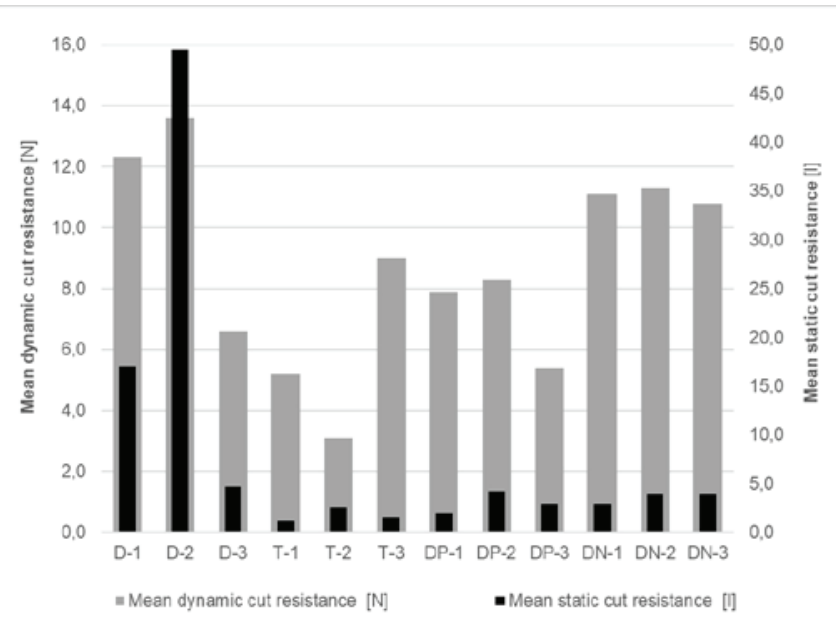

Figure 2. Comparison with the results of static and dynamic cut resistance. exhibited the highest resistance in both tests. The woven fabrics made of aramid, glass, and carbon fibers revealed lower cutting performance levels as compared with the knitted materials. The woven glass fiber fabric T-1 and woven aramid/carbon fiber fabric T-3 reached performance level 1 in terms of static cutting and level B in terms of dynamic cutting. Higher static cutting resistance was exhibited by the woven aramid fabric T-2, which revealed lower dynamic cutting resistance (level A). Silicone-coated knitted aramid fabrics were characterized by resistance to dynamic cutting at the same level $B$. In terms of static cutting, the coated aramid materials DP-2 and DP-3 reached performance level 2, while DP-1 reached level 1 . All dot-coated aramid fabric samples exhibited performance level 2 for static cutting resistance and level $\mathrm{C}$ for dynamic cutting resistance (the highest possible result, reached by only two other materials - the knitted aramid fabrics D-1 and D-2).

In terms of grip strength tests, the highest values were obtained by silicone-coated knitted aramid fabrics DP-2 (64.8 N) and

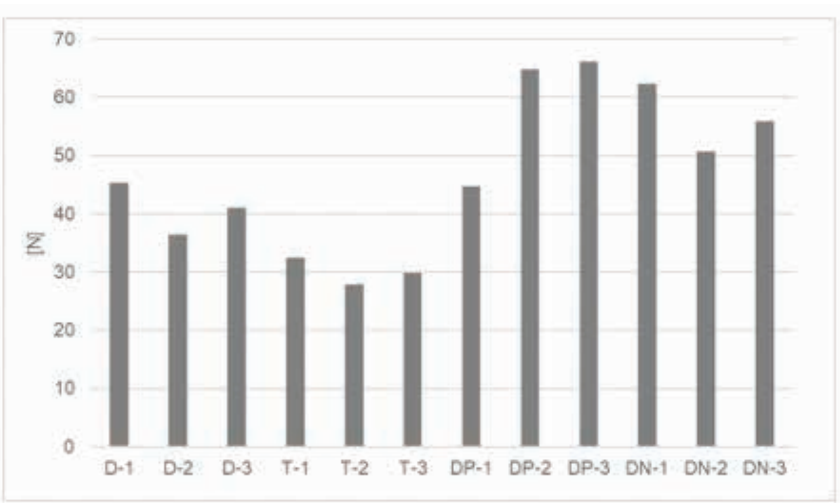

Figure 3. Grip strength test results.

Table 5. Static and dynamic cut resistance results

\begin{tabular}{|c|c|c|c|}
\hline Type of material & Sample designation & Mean static cut resistance (I) & $\begin{array}{c}\text { Mean dynamic cut resistance } \\
(N)\end{array}$ \\
\hline \multirow{3}{*}{ 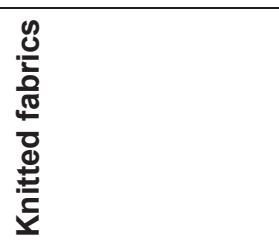 } & $\mathrm{D}-1$ & 17.0 & 12.3 \\
\hline & $\mathrm{D}-2$ & 49.5 & 13.6 \\
\hline & D-3 & 4.7 & 6.6 \\
\hline \multirow{3}{*}{ 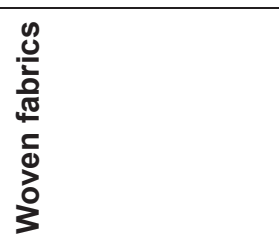 } & T-1 & 1.2 & 5.2 \\
\hline & T-2 & 2.6 & 3.1 \\
\hline & T-3 & 1.5 & 9.0 \\
\hline \multirow{3}{*}{ 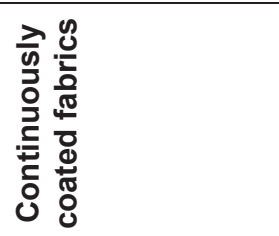 } & DP-1 & 1.9 & 7.9 \\
\hline & DP-2 & 4.2 & 8.3 \\
\hline & DP-3 & 2.9 & 5.4 \\
\hline \multirow{3}{*}{ 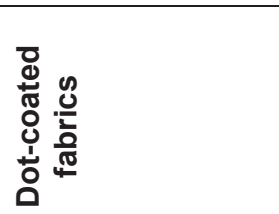 } & DN-1 & 2.9 & 11.1 \\
\hline & DN-2 & 3.9 & 11.3 \\
\hline & DN-3 & 3.9 & 10.8 \\
\hline
\end{tabular}


DP-3 $(66.3 \mathrm{~N})$, with similar results for the dot-coated knitted fabric DN-1 (62.4 N). The lowest grip strength was found for non-coated woven aramid fabrics T-2 $(27.8 \mathrm{~N})$ and T-3 $(29.9 \mathrm{~N})$, and the glass fiber woven fabric $\mathrm{T}-1(32.5 \mathrm{~N})$.

\subsection{Statistical analysis results}

Test results were analyzed statistically in terms of potential correlations between cut resistance and grip strength by calculating Pearson's $r$ coefficient. Table 6 presents descriptive statistics for static and dynamic cut resistance and grip strength obtained for the studied materials.

Table 7 contains a matrix of correlations between static and dynamic cut resistance and grip strength results for the studied materials.

Statistical analysis showed that the static and dynamic cut resistance of the studied protective materials was not significantly correlated with their grip force properties.

\section{Summary and conclusion}

The study involved cut resistance tests under constant and varied cutting forces. Besides, a non-standard grip force test was used to investigate potential correlations between the cut resistance of materials and their grip strength properties. Thus, the current paper presents a preliminary study in determining optimum methods for evaluating cut-resistant materials, including biomimetic ones.

According to a considerable body of literature, the cut resistance of glove materials depends on the type of fibers they contain, their structure, and the finish of the fabric [8, 16, 31, 32]. The present study investigated the materials made of aramid, glass, and carbon fibers (Table 1).

The cutting mechanism has been reported to be significantly affected by factors such as the strain associated with the transverse deflection of fibers [33, 34], the intrinsic strength of the material [32], and friction between the blade and cut material [35].

The present study employed the cut resistance test methods prescribed in the standards EN 388:2016 + A1:2018 (static cutting) and EN ISO 13997:1999 (dynamic cutting). Among all the studied materials, the highest resistance to static cutting was found for the knitted aramid fabric D-2, woven aramid fabric T-2, continuously coated knitted aramid fabric DP-2, and dot-coated knitted aramid fabrics DN-2 and DN-3. In terms of dynamic cutting, the highest resistance was also found for the knitted aramid fabric D-2, and then for the woven aramid/ carbon fiber fabric T-3, continuously coated knitted aramid fabric DP-2, and dot-coated knitted aramid fabric DN-2.

Besides, the studied textile materials were evaluated using a grip strength test (Figure 1), which provided indirect information about their anti-slip properties. Those properties are of great relevance to user comfort and ergonomics, as they significantly affect grip strength $[1,10,36]$. The highest grip strength was exhibited by the knitted aramid fabric D-1, woven glass fiber fabric T-1, silicone-coated knitted aramid fabric DP-3, and dotcoated knitted aramid fabric DN-1.

Many authors have investigated the process of cutting protective materials. In their study of cutting mechanics, Vu Thi et al. [37] reported that cut resistance arises from an interplay of two factors: intrinsic material strength and friction [35]. An increase in friction may enhance or reduce cut resistance as the overall energy required to cut through a material depends on the friction coefficient: the loss of energy dissipated by the force compressing laterally the blade sides exerted by the material and resulting from its elasticity (bending rigidity) [35]. Consequently, the present authors found major differences in cutting mechanics between coated and non-coated textile materials. In the former case, the process of cutting involves two types of frictional forces: the force of macroscopic friction arising from the normal force applied to both sides of the blade and the sliding friction associated with the cut being propagated through the material (which occurs along the face of the blade).

This study involved both continuously coated and dot-coated materials (Table 1). The application of polymeric dots, which form spatial, and sometimes layered, structures was to some extent inspired by bionic structures. Indeed, according to a substantial body of research, bionics-inspired solutions can substantially enhance mechanical properties as compared to conventionally engineered ones [38, 39], such as layer [40], plate [29], foam [41, 42], and hybrid layer structures [43, 44]. Although the abovementioned publications reported high mechanical strength of the developed structures, they have yet to be validated and optimized. The present study also involved some bionics-inspired textile materials with biomimetic grip dots (Table 1).

Table 7. Matrix of correlations between static and dynamic cut resistance and grip strength

\begin{tabular}{|l|c|c|c|}
\hline & & \multicolumn{2}{|c|}{ Grip strength $(\mathrm{N})$} \\
\hline & & Pearson's $\boldsymbol{r}$ & $\boldsymbol{p}$ \\
\hline \multirow{3}{*}{ Cut resistance } & Static $(I)$ & -0.19 & 0.55 \\
\cline { 2 - 4 } & Dynamic $(N)$ & 0.22 & 0.50 \\
\hline
\end{tabular}

Table 6. Descriptive statistics for static and dynamic cut resistance and grip strength tests

\begin{tabular}{|c|c|c|c|c|c|c|}
\hline & & $\boldsymbol{N}$ & Min & Max & $M$ & $S D$ \\
\hline Cut resistance & Static (I) & 12 & 1.20 & 49.46 & 8.02 & 13.70 \\
\hline & Dynamic $(N)$ & 12 & 3.10 & 13.55 & 8.67 & 3.19 \\
\hline Grip strength (N) & & 12 & 27.80 & 66.26 & 46.49 & 13.61 \\
\hline
\end{tabular}


It should be noted that Moreland [45] did not find any correlation between the tensile strength and cut resistance of fibers. While in that study glass fibers exhibited much higher cut resistance than p-aramid fibers with the same area density, the latter were characterized by greater tensile strength. Furthermore, in some cases of polymer-coated materials, cut resistance was enhanced due to the effects of friction. Similarly, also in this study, dot-coated aramid fabrics (DN-1, DN-2, and DN-3) revealed superior dynamic cut resistance as compared to the corresponding non-coated fabrics (D-3, Table 5).

While the highest grip strength was found for the continuously coated knitted aramid fabrics DP-2 and DP-3 as well as dotcoated knitted aramid fabrics DN-1 and DN-3 (Figure 3), statistical analysis (Table 7) did not reveal any correlations between those results and static or dynamic cut resistance.

The study revealed no correlations between the cut resistance of protective materials and their grip strength associated with anti-slip properties. Thus, in the case of cut-resistant materials, including biomimetic ones, the selected grip strength test method is not suitable for objective evaluation of cutting performance as affected by macroscopic frictional forces.

\section{ACKNOWLEDGMENTS}

This paper has been based on the results of a research task carried out within the scope of the fifth stage of the National Program "Improvement of safety and working conditions" partly supported in 2020-2022 — within the scope of research and development - by the Ministry of Science and Higher Education/National Centre for Research and Development. The Central Institute for Labour Protection - National Research Institute is the Program's main coordinator.

\section{References}

[1] Irzmańska, E., Tokarski, T. (2017). A new method of ergonomic testing of gloves protecting against cuts and stabs during knife use. Applied Ergonomics, 61, 102-114.

[2] Claudon, L. (2006). Influence on grip of knife handle surface characteristics and wearing protective gloves. Applied Ergonomics, 37, 729-735.

[3] Yu, A., Yip, J. (2019). Case study on the effect of fit and material of sports gloves on hand performance. Applied Ergonomics, 75, 17-26.

[4] Eurostat. (2020). Web site: https://ec.europa.eu/eurostat/ statistics-explained/index.php?title=Accidents_at_work statistics_by_economic_activity\#Analysis_by_injured_ body_part (accessed 10 October 2020).

[5] Li, D. X. (2020). Cut protective textiles. The textile institute book series. Elsevier.

[6] Dianat, I., Haslegrave, C., Stedmon, A. (2012). Methodology for evaluating gloves in relation to the effects on hand performance capabilities: A literature review. Ergonomics, 55(11), 1429-1451.

[7] Dianat, I., Haslegrave, C. M., Stedmon, A. W. (2014). Design options for improving protective gloves for industrial assembly work. Applied Ergonomics, 45(4), 1208-1217.
[8] Rebouillat, S., Steffenino, B. (2006). High performance fibres and the mechanical attributes of cut resistant structures made therewith. Conference: High Performance Structures and Materials, WIT Transactions on the Built Environment, 85, 279-299.

[9] Harrabi, L., Dolez, P., Vu-Khanh, T. (2008). Evaluation of the flexibility of protective gloves. International Journal of Occupational Safety and Ergonomics (JOSE), 14(1), 6168.

[10] Roda-Sales, A., Sancho-Bru, J. L., Vergara, M. GraciaIbáñez, V., Jarque-Bou, N. J. (2020). Effect on manual skills of wearing instrumented gloves during manipulation. Journal of Biomechanics, 98, 109512.

[11] Yoo, I.-G., Lee, J., Jung, M.-Y., Lee, J.-H. (2011). Effects of wearing the wrong glove size on shoulder and forearm muscle activities during simulated assembly work. Industrial Health, 49(5), 575-581.

[12] Irzmańska, E., Stefko, A. (2012). Comparative evaluation of test methods for cut resistance of protective gloves according to polish standards. Fibres and Textiles in Eastern Europe, 5(94), 99-103.

[13] Regulation (EU) 2016/425 of the European Parliament and of the council of 9 March 2016 on personal protective equipment and repealing Council Directive 89/686/EEC; 2016.

[14] EN 388:2016+A1:2018. (2018). Protective gloves against mechanical risks.

[15]EN ISO 13997:1999. (1999). Protective clothing Mechanical properties- Determination of resistance to cutting by sharp objects.

[16] Lara, J., Massé, S. (2020). Evaluating the cutting resistance of protective clothing materials. Proceedings of the 1st European Conference on Protective Clothing (ECPC) and NOKOBETEF 6 "Ergonomics for Protective Clothing", Sweden.

[17] Lara, J., Vu Thi, B. N., Vu-Khanh, T. (2003). Effects of friction on cut resistance of protective materials. Proceedings of the Second European Conference on Protective Clothing (ECPC) and NOKOBETEF 7 "Challenges for Protective Clothing", Switzerland.

[18] Lara, J. (2007). Need for reliable reference materials - Standard cut test method 13997 as an example. Proceedings of the 8th European Seminar on Personal Protective Equipment, Finland.

[19] Capdevila, F. X., Carrera-Gallissa, E., Escusa, M, Rotela, M. (2020). Canonical analysis of the Kawabata and sliding fabric friction measurement methods. Journal of the Textile Institute, 111(6), 890-896.

[20] Chassagne, F., Benoist, E., Badel, P. (2020). Characterization of fabric-to-fabric friction: Application to medical compression bandages. AUTEX Research Journal, 20(2), 220-227.

[21] Bertaux, E., Lewandowski, M., Derler, S. (2007). Relationship between friction and tactile properties for woven and knitted fabrics. Textile Research Journal, 77(6), 387-396.

[22] Wasilewski, T., Żuchowski, J., Ogorzałek, M., et al. (2014). Tribological tests as a new method for quality assessment of fabric softeners. Scientific Journal of Gdynia Maritime University, 86, 269-275 (in polish). 
[23] Lurie-Luke, E. (2014). Product and technology innovation: What can biomimicry inspire. Biotechnology Advances, 32, 1494-1505.

[24] Nachtigall, W. (2002). Biologisches design: Systematischer Katalog für bionisches Gestalten. Springer Verlag.

[25] Nachtigall, W. (2010). Bionik als Wissenschaft: Erkennen Abstrahieren. Springer Verlag.

[26] Blok, V., Gremmen, B. (2016). Ecological Innovation: Biomimicry as a new way of thinking and acting ecologically. Journal of Agricultural Environmental Ethics, 29, 203-217.

[27] Bhushan, B. (2009). Biomimetics: Lessons from nature An overview. Philosophical Transactions of Royal Society A, 367, 1445-1486.

[28] Fan, Z., Lu, G., Liu, K. (2013). Quasi-static axial compression of thin-walled tubes with different crosssectional shapes. Engineering Structures, 55(Supplement C), 80-89.

[29] Zheng, B., Zhang, K., Yang, B., Liu, J. (2019). Ballistic performance and energy absorption characteristics of thin nickel-based alloy plates at elevated temperatures. International Journal of Impact Engineering, 126, 160-171.

[30] EN 1082-1:1996. (1996). Protective clothing. Gloves and arm guards protecting against cuts and stabs by hand knives Chain mail gloves and arm guards.

[31] Rebouillat, S., Steffenino, B., Miret-Casas, A. (2010). Aramid, steel, and glass: Characterization via cut performance testing, of composite knitted fabrics and their constituent yarns, with a review of the art. Journal of Materials Science 45(19), 5378-5392.

[32] Mayo, J. B., Wetzel, E. D. (2014). Cut resistance and failure of high-performance single fibers. Textile Research Journal, 84(12), 1233-1246.

[33] Shin, H. S., Erlich, D. C., Shockey, D. A. (2003). Test for measuring cut resistance of yarns. Journal of Materials Science, 38, 3603-3610.

[34] Knoff, W. (2001). The effect of moisture and heat treatment on the lateral compressive properties of PPTA fibres. Proceedings of the 30th Textile Research Symposium, Shizuoka, Japan, 45-53.
[35] Vu Thi, B. N., Vu-Khanh, T., Lara, J. (2005). Effect of friction on cut resistance of polymers. Journal of Thermoplastic Composite Materials, 18(1), 23-35.

[36] Barker, R., Ross, K. Andrews, J., Deaton, A. S. (2017). Comparative studies on standard and new test methods for evaluating the effects of structural firefighting gloves on hand dexterity. Textile Research Journal, 87(3), 270-284.

[37] Vu Thi, B. N., Vu-Khanh, T., Lara, J. (2009). Mechanics and mechanism of cut resistance of protective materials. Theoretical and Applied Fracture Mechanics, 52, 7-13.

[38] Abbasi, M., Reddy, S., Ghafari-Nazari, A., Fard, M. (2015). Multiobjective crashworthiness optimization of multicornered thin-walled sheet metal members. Thin-Walled Structures, 89, 31-41.

[39] Liu, W., Lin, Z., Wang, N., Deng, X. (2016). Dynamic performances of thin-walled tubes with star-shaped cross section under axial impact. Thin-Walled Structures, 100(Supplement C), 25-37.

[40] Rong, Y., Liu, J., Luo, W., He, W. (2018). Effects of geometric configurations of corrugated cores on the local impact and planar compression of sandwich panels. Composite Part B: Engineering, 152, 324-335.

[41] Shen, J., Lu, G., Ruan, D. (2010). Compressive behaviour of closed-cell aluminium foams at high strain rates. Composites Part B Engineering, 41(8), 678-685.

[42] Lu, G., Shen, J., Hou, W., Ruan, D., Ong, L. S. (2008). Dynamic indentation and penetration of aluminium foams. International Journal of Mechanical Sciences, 50(5), 932943.

[43] Martini, R, Barthelat, F. (2016). Stretch-and-release fabrication, testing and optimization of a flexible ceramic armor inspired from fish scales. Bioinspiration \& Biomimetics, 11, 066001.

[44] Meyers, A., Lin, Y. S., Olevsky, E. A., Chen, P.-Y. (2012). Battle in the Amazon: Arapaima versus Piranha. Advanced Engineering Materials, 14(5), 279-288.

[45] Moreland, J. (2010). Production and characterization of aramid copolymer fibers for use in cut protection, Clemson University. 